\title{
A parresía pedagógica de Foucault e o êthos da educação como psicagogia*
}

\author{
ALEXANDRE SIMÃO DE FREITAS \\ Universidade Federal de Pernambuco
}

Nossa exposição pretende explorar algumas dimensões dos usos recentes do pensamento foucaultiano pelo campo educacional brasileiro, partindo do pressuposto de que está ocorrendo uma nova recepção das suas ideias impulsionada pela edição dos cursos inéditos proferidos no Collège de France entre 1982 e 1984. A publicação recente desse material tem permitido observar uma face pouco conhecida do pensador: a face do agora denominado Foucault professor (Noguera-Ramírez, 2008). Uma face que tem se revelado potente na criação de novas ferramentas conceituais e metodológicas.

Nesse aspecto, é bastante curioso observar o impulso que as reflexões sobre a temática da formação humana vêm adquirindo em articulação com múltiplos usos do pensamento tardio de Foucault (Carvalho, 2010; Dalbosco, 2010; Gallo, 2008; Herman, 2010; Pagni, 2010), sendo já possível apreender, inclusive, a cristalização de algumas temáticas privilegiadas, como: biopolítica e governamentalidade, cuidado de si e espiritualidade, experiência formativa e processos de subjetivação, o que indica que por que se lê Foucault hoje é bastante diferente do por que se lia Foucault há vinte anos no campo educacional, em geral, e brasileiro, em particular. A reflexão insere-se, portanto, em um projeto mais amplo de pesquisa que explora, por um lado, a cartografia da presença atual de Foucault, junto aos educadores, em meio aos problemas de recepção e crítica, articulando-a com o crescimento significativo de trabalhos voltados para uma analítica da noção e da experiência do cuidar de si, e, por outro lado, investiga as figuras éticas e políticas do cuidado abordadas no debate pedagógico contemporâneo.

* Trabalho apresentado na 35a Reunião Anual da Associação Nacional de Pós-Graduação e Pesquisa em Educação (ANPEd), 2012, no Grupo de Trabalho Filosofia da Educação (GT-17). 
Sabe-se que nas últimas três décadas a noção de cuidado tem emergido com cada vez mais insistência tanto no âmbito da teorização filosófica quanto na teorização educacional. Não obstante, observa-se também uma indistinção semântico-pragmática a respeito do termo. Como sinaliza Irene Borges-Duarte (2010), se é preciso admitir que o termo transformou-se em uma noção, o fato é que ainda não atingiu o estatuto efetivo de conceito. Situação que merece ser problematizada, tendo em vista que, na atualidade, tanto os aparelhos governamentais quanto as organizações não governamentais vêm propondo políticas e práticas ancoradas nos princípios derivados de uma ética do cuidado que parecem se mover no sentido de uma gestão calculada da vida.

Dessa forma, o objetivo específico deste texto consiste em evidenciar como a tematização em torno do cuidado de si emerge como um acontecimento no pensamento, através do qual os educadores são incitados a se situarem tanto em termos filosóficos quanto em termos pedagógicos. Isso porque, segundo Humberto Castrillón (2003, p. 201), ao abordar a noção de cuidado de si, Foucault acabou produzindo insights inovadores sobre os processos de subjetivação que guardam estreitas relações com questões éticas, políticas e pedagógicas, historicamente, problematizadas no âmbito da tradição da Bildung. Para esse autor, as reflexões tardias de Foucault afetam, sobretudo, a representação que temos da pedagogia e das suas categorias, bem como os seus campos hegemônicos de formação discursiva. Nesse sentido, as análises foucaltianas do cuidado de si articulam uma crítica severa aos processos de produção de "um sujeito do saber que é o sujeito que se identifica, acata, faz seu esse saber até o ponto que esse se vê assujeitado por esse saber, embora não reconheça a sujeição, antes considera que ser sujeito do saber é uma liberação" (idem, ibidem), apontando, nesse percurso, a cegueira dessa verdade de caráter eminentemente pedagógico.

No entanto, de forma paradoxal, muitas das leituras sobre e a partir de Foucault conduzidas no campo pedagógico ainda têm servido para legitimar o saber e o sujeito do saber e não para refutá-los, ignorando que, ao tematizar o si mesmo e os processos de subjetivação, Foucault aponta a superação da "pedagogia como saber", indicando outros modos de mover as ações pedagógicas em nossa atualidade. Nos termos assumidos nesse trabalho, o problema reside no fato de que, embora os termos sujeito e subjetividade estejam incorporados na tradição pedagógica, o mesmo não acontece com a noção de si mesmo. Essa noção, gravemente ignorada, indica uma compreensão do saber distinta da lógica normalizadora disciplinar ou biopolítica, na qual educar se realiza pelo apoio, seja da lei e da norma, seja da regulamentação e do controle, tudo em meio a uma pedagogia que se quer, ela mesma, saber e ciência.

Assim, se é verdade que já nos anos de 1990 desdobra-se toda uma reflexão em torno das práticas de subjetivação, a tematização da formação do si mesmo permanece ausente das reflexões pedagógicas. Ignora-se sua pertinência tanto para a problemática filosófica quanto pedagógica; pertinência já contida em um dos mais antigos testemunhos do pensamento ocidental: o fragmento heraclitiano êthos anthrópo daimon cuja tradução corrente é "o caráter é para o homem seu daimon" (Agamben, 2008, p. 173, tradução minha), e que indica outras formas de pensar o modo de ser próprio do homem. Além disso, de nossa parte, assumimos também que a problematização da ética do cuidado e 
do sujeito do cuidado de si pode trazer elementos para ultrapassar os impasses que têm paralisado a teorização educacional crítica, tanto no que se refere à fundamentação da ação docente e da racionalidade pedagógica (Dalbosco, 2010), quanto na hegemonia de uma prática pedagógica que insiste na produção objetivada do sujeito da educação.

Em outras palavras, a reflexão sobre o si mesmo, subjacente à ética do cuidado foucaultiana, permite vislumbrar duas pedagogias: uma que se volta para a produção do sujeito e outra que visa transformá-lo. Essa dimensão bipolar da educação, que pode ser encontrada em quase todas as sociedades (Castrillón, 2003, p. 204), foi localizada, com uma precisão analítica surpreendente por Michel Foucault, na Antiguidade greco-romana, através da diferenciação entre pedagogia e psicagogia. Com essa percepção, desenvolvemos o fio argumentativo dessa reflexão, a partir de dois movimentos. Inicialmente, apresentamos uma breve reconstrução da recepção do pensamento foucaultiano no campo educacional brasileiro, pois admitimos que a publicação dos cursos tardios vem delineando um novo movimento de apropriação das suas ideias. Em seguida, analisamos como o seu dizer parresiástico em torno do cuidado de si indica novas cifras para a problematização da educação, focalizando especificamente a diferença analítica entre pedagogia e psicagogia com o fim de extrair implicações para o debate em torno da formação humana na contemporaneidade.

\section{A REATIVAÇÃO DA NOÇÃO DE CUIDADO DE SI: NOTAS PARA UMA RECEPÇÃO EM CURSO}

De acordo com Silvio Gallo (2008) e Alfredo Veiga-Neto (2009), a influência do pensamento foucaultiano na educação pode ser compreendida a partir dos impactos da publicação da edição brasileira de Vigiar e punir em 1977. Nesse momento, produziram-se inúmeros trabalhos que privilegiaram a questão do disciplinamento e da normalização. Uma ênfase que permanece "como referência para muitos estudos históricos, sociológicos e pedagógicos sobre a Educação" (idem, p. 13), o que contribuiu para afetar a imagem e os usos que se fazem do pensamento de Foucault junto aos educadores. Essa situação seria parcialmente alterada quando, nos anos de 1990, ocorre um novo impulso de investigações, sobretudo a partir da focalização das "tecnologias do eu colocadas em funcionamento pela pedagogia moderna” (idem, ibidem).

Apesar disso, a compreensão é que apenas uma pequena parte dessas pesquisas teria se ocupado efetivamente em investigar o domínio da ética foucaultiana em articulação direta com as questões do campo pedagógico. Pois é somente nos anos 2000, com a influência direta das publicações das entrevistas e artigos de Foucault, editadas nos Ditos E' Escritos, e dos cursos proferidos por Foucault no Collège de France (1978-1984), que "se entende melhor o recuo histórico e o correlativo deslocamento temático que Foucault efetuou ao entrar no terceiro domínio da sua obra - domínio do ser consigo" (idem,p. 14). Posição partilhada por Carlos Noguera-Ramírez (2008) que defende que, ao contrário das obras publicadas, os últimos cursos de Foucault permitem uma releitura de todo seu aporte teórico, expandindo uma série de estudos ancorados em uma elaboração renovada de conceitos como verdade, poder, governo, ascese, dentre outros. 
Mais ainda: a edição e publicação dos cursos possibilita uma retomada do próprio itinerário intelectual de Foucault, abrindo novas leituras e novos usos do seu pensamento no campo educacional. Como ressalta Pedro Pagni (2011, p. 20),

[...] tal retomada não significa pura e formalmente dar conta de um projeto filosófico somente para apreendê-lo em sua totalidade, mas, sim, analisar e pensar os problemas e acontecimentos emergentes na atualidade e que nos desafiam como sujeitos deste tempo presente. [...] verificar em que medida a publicação dos textos inéditos e a transcrição das aulas dão maior coesão às suas ambições originais ou as modificam no sentido de aprimorá-las, ao mesmo tempo em que se analisa até que ponto nos auxiliam a pensar de outro modo aqueles problemas e acontecimentos do presente, assim como nos modificar para tal, contribuindo para desfazer mal entendidos de interpretações e de apropriações anteriores, tentando configurá-lo com mais justeza em relação aos seus princípios e mais atualidade em relação aos seus fins.

José Ternes (2007), na mesma direção, apresenta uma análise sugestiva ao comparar as décadas anteriores e o momento atual das pesquisas foucaultianas. Ele afirma que "os educadores, talvez por suas raízes marxistas, não conseguem pensar senão à sombra do político” (idem, p. 23). Desse modo, é tão somente com a flexibilização dessa tendência e depois da tradução dos cursos do Collége de France que começaram a emergir estudos voltados para os textos mais tardios de Foucault. ${ }^{1}$

$\mathrm{O}$ fato é que, nesse momento, as temáticas relativas à estética da existência, aos processos de subjetivação e ao cuidado ético de si mesmo são apresentadas de forma tão provocadora que chega a desconcertar os seus intérpretes. Nesse cenário, segundo Margareth Rago (2009, p. 264), "os críticos de Foucault passaram a discutir se estaria ocorrendo um 'retorno ao sujeito' em seu pensamento". Nos seus termos, isso significa que "páginas e páginas foram escritas, acusando ou defendendo essa tese" (idem, ibidem), desviando o olhar dos educadores das novas problematizações e submergindo as análises de Foucault na reafirmação do mesmo. Essa situação parece estar relacionada também à incompreensão de um conjunto de temas que passaram a configurar o corpus foucaultiano, tais como as noções de ascese, espiritualidade, parresía e amizade (Ortega, 1999). Diagnóstico confirmado com a percepção de que os processos de recepção da obra tardia de Foucault estavam obstruídos por um tratamento superficial da noção de governamentalidade, o que impediu de ver os desdobramentos e as articulações entre os temas da resistência e do governo na fase final de seu pensamento.

Como consequência, os intérpretes têm falhado ao abordar a ética do cuidado de si em sua relação direta com os processos de governamentalização e subjetivação. Um exemplo claro dessa dificuldade aparece na aproximação linear dos conceitos de

1 Ternes (2007, p. 23) observa que existe ainda um terceiro campo de estudos foucaultianos pouco explorado pela educação brasileira: "trata-se dos estudos de Foucault acerca dos saberes da cultura ocidental", a partir dos quais é possível dar atenção às condições do próprio pensar. 
governo e cuidado nas discussões recentes. Tomando essas noções como sinônimas, sem as devidas mediações, várias análises produzem um viés que reduz o cuidado de si ao mero exercício de um domínio (notadamente no uso das paixões e dos desejos), tendo em vista uma melhor administração das nossas relações com os outros.

Esse tipo de análise alimenta um matiz utilitarista-pragmático claramente ausente na discussão que Foucault realiza em torno do cuidado de si. Nesse aspecto, Walter Kohan (2011), ao discutir o "último Sócrates do último Foucault", destaca que o próprio autor chama a atenção para o verbo kbráomai (servir-se de), sobre o qual "recai [toda] a argumentação platônica do Alcibíades, entre 129c e 130a, mas não se refere ao verbo árkhomai (mandar, governar), que sintetiza a relação entre corpo e alma (em 130a-c), e [que] é sobretudo um verbo que expressa poder" (idem, p. 57), apontando claramente que o campo semântico do cuidar configura-se como uma linha de fuga aos modos hegemônicos de exercício do poder. A justeza desse argumento pode ser observada em uma leitura cuidadosa do curso de 1983, Governo de si e dos outros, no qual Foucault insiste que Sócrates não joga o jogo da confissão e do tribunal, pois a finalidade do cuidado não seria corretiva e sua ética não seria uma ortopedia.

Essa é a razão pela qual consideramos de fundamental importância recuperar, ainda que brevemente, a análise foucaultiana em torno da psicagogia, pois encontramos nesse âmbito não apenas uma reflexão direta da educação em estreita articulação com as temáticas do cuidado e da parresía, mas, sobretudo, porque essa pode ser uma via importante para uma crítica a determinados usos que se tem feito da ética do cuidado no campo pedagógico em estreita vinculação com o discurso do empreendedorismo de si (Gadelha, 2009) e da autoajuda, no qual o cuidado de si se transforma em estratégia de gerenciamento do conhecimento escolar, incluindo as dimensões emocional e relacional, com vistas a extrair lições pedagógicas para o alcance de uma vida feliz e bem sucedida, através do reencantamento pastoral da função docente. $O$ contexto de tematização da psicagogia por Foucault visa, ao contrário, uma atitude crítica face aos saberes do ser humano sobre si mesmo e logo face à reflexão filosófica da educação.

\section{UM DISCURSO PARRESIÁSTICO SOBRE A EDUCAÇÃO: FOUCAULT COMO UM CRÍTICO DA PEDAGOGIA}

Como indica o trabalho seminal de Andrés Peña (2003), a tematização do cuidado de si, no pensamento tardio de Foucault, põe em cena um gesto pedagógico radical. Para esse autor, Foucault apresenta uma análise inovadora das possibilidades de constituição do sujeito, tomando como ponto de partida a noção de si mesmo para diferenciar o sujeito das práticas de subjetivação ética, do sujeito epistêmico. Com isso, diferentemente do que se observa nas obras publicadas do autor, nos cursos do Collège de France, a racionalidade pedagógica é diretamente problematizada, desvelando o acesso a outras formas de educar o sujeito através do preceito do cuidado de si. Por meio da articulação entre processos de subjetivação e práticas do cuidado de si, novas questões e novas categorias são mobilizadas para repensar a agenda pedagógica. De forma surpreendente, as reflexões travadas contribuem para que a análise educacional 
se distancie tanto das verdades derivadas do sujeito-identidade quanto do poder normalizador das ciências humanas, tomando por base o fato de que a distinção entre os exercícios de transformação de si e o esclarecimento filosófico configura-se como uma diferenciação recente nas práticas pedagógicas do Ocidente.

Por isso, não casualmente, os cursos tardios foram caracterizados como ambíguos (Gros, 2004, p. 613), uma vez que aí Foucault discute um fenômeno que, apesar de ser bastante difundido, permanece ainda inexplorado: uma modalidade de sujeito que se autoconstitui mediante práticas específicas de relação consigo mesmo. O mais estranho e inquietante nessa reflexão é o fato dessa busca aparecer imbricada com questôes espirituais. Foucault (2004, p. 21), nesse aspecto, chega a ser incisivo ao defender que o ato de conhecer comporta "toda a estrutura de um ato espiritual". Contudo, a estranheza gerada por essa afirmação não decorre apenas do fato de Foucault recorrer a antigos filósofos gravemente subestimados pelo campo pedagógico, como alguns intérpretes têm assinalado, mas, sobretudo, em razão do próprio Foucault parecer incorporar, em suas análises, modos antigos de se praticar a experiência filosófica. Assim, ele mesmo parece estar plenamente consciente dos riscos envolvidos na reflexão que resolve colocar em movimento, tendo em vista que a imbricação entre o cuidado de si e a forma de pensamento denominada por ele de espiritualidade, ${ }^{2}$ produz um significativo desconforto nos nossos atuais sistemas de pensamento.

Isso, entretanto, parece não ter demovido Foucault da convicção da importância do uso dessa noção, tanto que ele insiste, em um passo decisivo na argumentação do curso de 1982, considerado uma espécie de marco nas suas análises do cuidado de si, na diferença entre o "saber da espiritualidade" e "saber do conhecimento" (idem, p. 374); diferença por meio da qual se articula uma crítica potente ao foco epistemológico dado às relações entre sujeito e verdade na modernidade. Para além do caráter polêmico de sua leitura do discurso filosófico da modernidade, pelo deslocamento de ênfase do exercício espiritual ao método intelectual, a desarticulação entre filosofia e espiritualidade também é carregada de consequências para a reflexão pedagógica, pois demarca o fato de que o acesso à verdade não estaria mais na dependência de um processo de autoformação ou formação de si mesmo.

Por essa via, a cisão entre filosofia e espiritualidade, enunciada por Foucault, mostra que a formação de si exige pôr em jogo processos que permitam a um sujeito qualquer adquirir, de um lado, discursos verdadeiros de que se tem necessidade em determinadas circunstâncias da vida e, por outro, fazer de si mesmo um sujeito ativo desses discursos. Essa é a razão pela qual ele insiste em um conjunto articulado de distinções que se desdobram polarizadas ao longo dos seus cursos tardios: cuidado de si e conhecimento de si; saber de espiritualidade e saber de conhecimento; conhecimentos inúteis e conhecimentos úteis; filosofia e retórica; filosofia e pedagogia. Foucault aciona

2 Nos termos de Salma Muchail (2011, p. 88), a espiritualidade é uma “noção vaga e perigosa”, podendo induzir a "equívocos místicos, esotéricos, religiosos". Apesar disso, a mesma autora reconhece que, "vasculhando todo o curso, percebe-se que a noção reaparece - mesmo se meramente nomeada - em praticamente todas as aulas" (idem, ibidem). 
esse conjunto de clivagens conceituais e metodológicas que emergem da diferenciação primeira entre filosofia e espiritualidade, e que visam articular a separação entre o conhecimento apreendido como ornamento da cultura e o conhecimento que modifica a natureza mesma do sujeito, ou melhor, a sua maneira de agir, o seu êthos. Tudo isso, culminando no anúncio de um termo desajeitado: psicagogia, contraposto, por sua vez, ao termo pedagogia. $\mathrm{Na}$ argumentação foucaultiana, a psicagogia abordaria e incluiria dimensões do fazer educativo que a pedagogia moderna deixou de tematizar, uma vez que não se apreende mais como uma arte da existência. Embora já esteja presente no curso de 1982, é no ano seguinte, no âmbito das reflexões sobre o Governo de si e dos outros, que essa diferenciação entre pedagogia e psicagogia adquire maior visibilidade.

\section{DA PEDAGOGIA COMO PSICAGOGIA À FILOSOFIA COMO PAIDEIA}

No curso intitulado Governo de si e dos outros (de 1983), enquanto estabelece as bases ético-políticas da parresía, Foucault apresenta uma visão sui generis do saber e da prática pedagógica enquanto vetor de transformação ética dos sujeitos. Contrapondo-se a uma visão do saber pedagógico como algo positivo, ou seja, como um saber que constrói um sujeito e um objeto para a educação e, consequentemente, da pedagogia como disciplina e como estratégia de governo e normalização, no curso de 1983 emerge uma perspectiva da educação como uma arte da existência e do cultivo de si.

Foucault propõe que a pedagogia é, antes de tudo, o locus de emergência de uma experiência de si (Castrillón, 2003, p. 213). Essa noção de experiência de si, na esteira de Goethe e Nietzsche, se caracterizaria como uma experiência de dessubjetivação, uma experiência limite cujo fim seria o desprendimento de si por meio de uma relação intensa de si a si; uma experiência de "deixar-ser, de transformar-se". O contexto mais amplo desse debate é duplo: por um lado, o problema do "real" da filosofia aprendida, ela mesma, enquanto uma prática de si; por outro, a oposição entre filosofia e retórica. Assim, Foucault evidencia uma prática filosófica que opera como uma pedagogia, pois o que visa o exercício filosófico é a transformação do sujeito que escreve, lê, tem experiências e busca no prazer da conversação e da companhia do outro a sabedoria e a felicidade. Nunca é demais ressaltar que sua definição de filosofia consiste, justamente, em um ensaio de transformação de si mesmo. E, através da clivagem entre filosofia e retórica, Foucault (2011, p. 350) extrai as implicações de um dizer-verdadeiro genuinamente filosófico, apresentando a parresía socrática como uma atividade psicagógica, ou seja, como um modo de condução da alma.

Nesse momento, Foucault explicita quais seriam os problemas a serem retomados com essa perspectiva de análise: "problema da filosofia comparada à retórica, problema da psicagogia e da educação em função da política” (idem, p. 180). Problemas que serão retomados na aula de 2 de março de 1983 quando ele delimita para a filosofia o monopólio do exercício parresiástico. É justamente nesse ponto que a filosofia é identificada com a psicagogia, já que visaria uma "operação sobre as almas" (idem, p. 276), através da ação dos discursos. Essa identificação da filosofia com a psicagogia é sugestiva na medida em que exige, nos termos do próprio Foucault, uma paideia capaz de fornecer os 
instrumentos práticos necessários para que os sujeitos possam operar a distinção entre o (dizer e o fazer) verdadeiro e o (dizer e o fazer) falso. A filosofia como psicagogia trataria, portanto, dos efeitos dos discursos no sujeito, o que demandaria um processo formativo específico. Além disso, afirma Foucault (idem, p. 277),

[...] parece que podemos ver também, a partir dessa questão da parresía se esboçar a questão, fundamental também na Antiguidade, das relações entre, grosso modo, verdade e coragem, ou entre verdade é ética. Quem é capaz de fazer um discurso verdadeiro? Como se pode distinguir o discurso verdadeiro do discurso lisonjeiro? E qual deve ser do ponto de vista ético, do ponto de vista de uma coragem, aquele que empreende a separação entre o verdadeiro e o falso? Quem é capaz de ter a coragem da verdade? E qual é a educação necessária? Problema técnico: qual vai ser, por conseguinte, na educação, o ponto no qual deve se pôr ênfase?

Nessa série de questões vemos nascer com clareza uma reflexão a respeito dos métodos, dos conhecimentos e dos exercícios necessários para impulsionar uma dinâmica formativa direcionada ao dizer-fazer ético. Destacamos a compreensão de que para formar a si mesmo há uma exigência de que a cada instante cuidemos também de nós mesmos. No entanto, Foucault observa que a prática do cuidar de si não pode apresentar garantias prévias. Pois não se pode determinar, de antemão, que o evento do discurso, enunciado pelo mestre, vá efetivamente influenciar o modo de ser do discípulo. Decorrendo dessa situação incerta, subjacente ao processo formativo eticamente orientado, uma pergunta insistente de Foucault: qual é então, na educação, o ponto no qual se deve pôr ênfase? Qual relação é capaz de modificar o sujeito e fazê-lo acessar a verdade? É por meio dessas questões que a psicagogia passa a ser retomada, agora, não mais no domínio estrito da retórica.

A problematização da prática psicagógica é deslocada para o âmbito da própria relação mestre-discípulo, desvelando, mediante um gesto interpretativo ousado, o enigma para o destravamento da própria formação política: a diferenciação ética dos sujeitos que compõem a cidade. Por essa razão, lembra Foucault, há uma face desagradável, mesmo brutal, violenta, na educação como psicagogia, pois, por um lado, sendo diferente de um processo pedagógico convencional, não há aqui técnicas didáticas a serem aplicadas, por outro, ela conduz a um processo perigoso de singularização ética dos sujeitos capaz de colocar em risco as próprias instituições políticas e os poderes vigentes em jogo. A conclusão de Foucault não deixa de ser ainda mais surpreendente: a parresía filosófica, ou seja, a filosofia praticada como cuidado de si e como pedagogia (paideia) exige um modo específico de pôr em ação o discurso, no vínculo mestre-discípulo, que demanda não uma retórica, mas uma erótica já que a questão posta pela pedagogia, exercida como uma psicagogia, não é simplesmente a do sentido do saber ou o saber do sentido, mas propriamente o sentido da presença e a presença do sentido na relação formativa vivenciada entre mestres e discípulos.

Em outros termos, a pedagogia como psicagogia responde não a uma dúvida (de natureza epistemológica) da ordem do saber, mas a um modo de olhar e de ouvir a si mesmo e ao outro (de natureza prático-sensível). Com isso, o trabalho 
psicagógico não invoca uma hermenêutica, mas uma força intensiva capaz de colocar em suspensão os paradigmas e operações lógicas, ao mesmo tempo em que aproxima professores e alunos de uma verdade que se incorpora ética e existencialmente no próprio modo de viver a relação educativo-formativa, desdobrando, assim, uma imagem potente do pensamento pedagógico que passa a ser apreendido, simultaneamente, como pensamento poético e como pensamento amoroso.

Como diferentes autores têm ressaltado, o contexto imediato da reflexão sobre o cuidado de si assenta-se em uma crítica do déficit da pedagogia e das práticas eróticas, tal como vivenciadas na Antiguidade greco-romana. É nesse âmbito "que a produção de si se realiza em uma atitude especial de pensamento, elaborada na epimeleia como desdobramento essencial dos poderes éticos"(Fimiani, 2004, p. 104). O exercício formativo do cuidado ético seria ativado por uma palavra de amor. Por isso, afirma Muchail (2011, p. 33), "Sócrates, o que ama, é aquele que cuida de que Alcibíades cuide de si a fim de poder bem cuidar da cidade”. A questão política do cuidado está, portanto, subordinada ao problema do amor. Posição que está em congruência com a interpretação ousada de Victor Pinheiro (2011, p. 36) de que, para Sócrates, as "causas profundas" dos acontecimentos históricos que põem em crise a democracia ateniense relacionam-se à verdade do amor e ao modo como essa verdade é vivenciada pelos sujeitos, indicando na contenda político-poética em torno da figura ambivalente de Alcibíades o antagonismo entre oligarcas e democratas.

Nessa perspectiva, em que pese as importantes diferenças entre os pensamentos de Foucault (2004) e de Martha Nussbaum (1992), vale ressaltar um eixo de tematização comum que delimita, por meio das problematizações do cuidado de si, da parresía e da psicagogia, uma concepção renovada dos problemas que atravessam o campo pedagógico, através da delimitação da educação como uma arte de viver (Nehamas, 2005), em que se enfatiza o papel das emoções para o esclarecimento de questões de importância ética e política, cuja base é o pressuposto da possibilidade da afirmação de uma função cognitiva das paixões. As artes de viver são fundadas nas práticas de argumentação com vistas ao uso da verdade, tendo como guia central o compromisso entre desejo e razão, abrindo, segundo Portocarrero (2010, p. 98), "em toda sua amplitude, um campo de investigação da filosofia antiga, que, em um aparente paradoxo, apenas começa a se esboçar".

Disso deriva, sintetiza Muchail (2011, p. 33), que a relação estabelecida entre "a ambição política e sua condição ética é como que antecedida por outra que a fundamenta: a relação entre o mestre e o discípulo". Não há outra via para o desenvolvimento ético do cuidado de si mesmo senão a relação amorosa com o mestre. Mesmo admitindo a "mediação da cidade" (idem, p. 74), o cuidado de si diz sempre respeito a uma pedagogia incapaz de dar conta das suas metas formativas, sobretudo em relação aos jovens. Daí porque, nos termos de Foucault (2004, p. 107), é

[...] a propósito deste problema, neste vazio institucional, neste déficit da pedagogia, neste momento política e eroticamente conturbado do fim da adolescência e de ingresso na vida adulta - que se formou o discurso filosófico, ou pelo menos a forma socrático-platônica do discurso filosófico. 
Por isso, é possível observar também os limites de uma separação analítica rígida entre o foco do cuidado de si na leitura foucaultiana do Alcibíades (onde o cuidar visaria o conhecimento da alma) e do Laques (onde o cuidar visaria o bios, a vida), ${ }^{3}$ uma vez que a própria mediação do conhecimento de si pelas práticas de cuidado é o que permite fazer da própria vida uma obra: arte da vida, arte da existência. Arte da existência que se sustenta em um deslocamento radical do próprio registro pedagógico. Com efeito, é possível ressaltar, mesmo contrariando determinadas passagens da leitura de Foucault sobre os dois diálogos mencionados que, enquanto exercício psicagógico, a pedagogia apoia-se em práticas que se dirigem a um sujeito em transformação, realizando-se menos como uma arte de governar ou guiar, e mais como uma força de afetação sensível dos sujeitos. Assim, enquanto atividade prático-poética, a pedagogia geraria e difundiria discursos capazes de mobilizar ações, incitando a deliberação ética em torno de condutas aceitas ou de condutas a serem assumidas por si mesmo. Do que se depreende a afirmação de Foucault (idem, p. 494) de que a psicagogia sempre esteve "muito próxima da pedagogia" do mesmo modo que a filosofia se aproxima da espiritualidade. Uma proximidade paradoxal se levarmos em conta a definição que o próprio Foucault fornece da pedagogia como a "transmissão de uma verdade que tem por função dotar um sujeito qualquer de aptidões, capacidades, saberes, etc., que ele antes não possuía e que deverá possuir no final desta relação pedagógica”, e da psicagogia como a "transmissão de uma verdade que não tem por função dotar um sujeito qualquer de aptidões, etc., mas modificar o modo de ser do sujeito a quem nos endereçamos" (idem, p. 493). Essa diferenciação porta, entretanto, finalidades meramente didáticas, já que a psicagogia seria antes um modo outro de exercitar a pedagogia e experienciar os efeitos das práticas pedagógicas em si mesmo. ${ }^{4}$

O mais importante é perceber como, através de um giro desafiador para os educadores, Foucault aparece nos cursos tardios, ele mesmo, como um crítico e um amante da pedagogia. Pois se a noção de espiritualidade permitiu a ele retomar o cuidado de si como princípio crítico ao déficit da pedagogia, a noção de psicagogia possibilitou que Foucault recuperasse, no mesmo movimento, para a pedagogia, um lugar fundamental na superação dessa crise.

Por isso, diz Castrillón (2003, p. 214), o termo que melhor se aproxima do que Foucault pensa ser o si mesmo é o de formação (Bildung) enquanto uma experiência educativa de autotransformação. Para esse autor, todo o trabalho tardio de Foucault pode ser considerado como "uma obra de Bildung". Na sua leitura, ele pode figurar

3 Na impossibilidade de poder explorar, nos limites desse texto, a proposição de que na primeira leitura (a do Alcibiades) teríamos a abertura para uma metafísica e na segunda (a do Laques) uma estilística da existência (cf. Kohan, 2011, p. 63), indicamos que somos mais propensos a pensar, com Muchail (2011, p. 46), que apesar das transformações e deslocamentos da noção de cuidado, no pensamento socrático, ela persiste em sua "posição de fundamento do conhecimento".

4 Como ressalta acertadamente Noguera-Ramírez (2011, p. 33), essa diferenciação precisa ser apreendida mais como uma alteração na condução das práticas pedagógicas, "antes que como a constituição de dois tipos de práticas de diferente natureza". 
como um pedagogo. Não um pedagogo positivo produzido pelas instituições educativas, um teórico ou um cientista da educação, mas um pedagogo na medida em que seu pensamento emerge por dentro da tradição da Bildung apreendida como um trabalho de si sobre si mesmo que se obtém por vontade e experiência própria. Nesse sentido, Foucault não seria nem sábio nem instruído, seria, antes de tudo, alguém que luta para criar liberdades para si mesmo, para suportar seu ser próprio como sujeito, fazendo da sua própria experiência de professor, no Collège de France, ocasião de uma transformação radical nas relações que ele mesmo estabeleceu com os saberes institucionalizados e consigo mesmo como sujeito desses saberes.

\section{CONSIDERAÇÕES FINAIS}

Ao final dessa reflexão, é importante ainda colocar uma última questão: seria, então, casual o fato da retomada da noção de cuidado de si estar contribuindo para uma reativação do debate sobre a formação humana na atualidade? A resposta a essa questão não pode ser senão negativa, pois como vimos, ao longo deste trabalho, a problematização da estética da existência, agora, faz-se acompanhar de um crescimento significativo de temáticas como a espiritualidade, o cuidado de si e a parresía, apontando a emergência de uma nova recepção de Foucault entre os educadores.

Em recente publicação, Kohan (2011), ao refletir sobre as relações entre Sócrates e a educação, não se furtou em trazer uma análise detalhada das reflexões foucaultianas em torno do cuidado de si. Na mesma direção, Muchail (2011) também abordou o pensamento tardio de Foucault, apresentando-o sintomaticamente como um mestre do cuidado de si. O mesmo fenômeno se observa na produção acadêmica brasileira. Nyrluce Alves (2012), analisando o Banco de Teses da CAPES, encontrou 64 trabalhos, de áreas diversas, em que a noção de cuidado foi abordada nesse último decênio, sendo que, desse total, 24 pesquisas pertenciam ao campo educacional, indicando que essa área tem sido predominante quando se trata de trabalhos desenvolvidos a partir da noção de cuidado de si em chave foucaultiana.

Essa retomada da noção do cuidado de si, portanto, parece não se configurar como um fenômeno isolado, sendo importante considerar que, nesses trabalhos, tal noção tem sido articulada em uma aproximação estreita com a ideia da educação como formação humana, sendo nesse contexto que a noção adquire relevância para o campo educacional. $\mathrm{O}$ fenômeno é polêmico, justamente, porque está na contramão dos movimentos iniciais da recepção do pensamento de Foucault pelo campo educacional brasileiro nos anos de 1980 e 1990. Desse modo, os trabalhos ancorados no cuidado de si parecem ignorar tanto a imagem de Foucault classificado como um teórico do poder anti-humanista quanto como um niilista consumado e perigoso para a manutenção dos ideais éticos e políticos de caráter emancipatório na educação. Esse gesto interpretativo, sem dúvidas, carece ainda de maiores investigações.

Assim, consideramos a importância de leituras mais regulares e sistemáticas, no âmbito filosófico-educacional, que foquem no pensamento foucaultiano tardio, em geral, e no cuidado de si, em particular, desvelando os percursos e refinando as noções e 
categorias que foram mobilizadas por Foucault nos seus últimos cursos. Esse parece ser o caso da noção de psicagogia tematizada regularmente entre os cursos de 1982 a 1984.

Uma noção importante para a reflexão filosófica e educacional na medida em que permite questionar nossa compreensão de saber e de saber pedagógico, com consequências para a coordenação da ação docente (Dalbosco, 2010) e para explicitação dos elementos que configuram a práxis pedagógica na atualidade (Pagni, 2010). A pedagogia, apreendida pela perspectiva psicagógica, pode contribuir ainda para ressignificar as formas de experiência de si, abrindo vias concretas para que os sujeitos possam conduzir sua própria formação. De fato, por meio dessa noção, Foucault parece indicar aos educadores que é possível encontrar na própria história da cultura ocidental processos alternativos de formação do sujeito desconectados das postulações metafísicas ou utilitárias. Ao revisitar a problematização da pedagogia como psicagogia, sua reflexão configura-se enquanto um caminho fundamental não somente para a prática filosófica, mas como um princípio basilar de toda conduta pedagógica, produzindo ressonâncias curiosas entre, de um lado, o diagnóstico foucaultiano de que a filosofia grega resultaria de um déficit da pedagogia, e, de outro, a percepção contemporânea de que é preciso revisitar, filosoficamente, a noção de formação humana como forma de fazer face à crise da racionalidade pedagógica em suas múltiplas manifestações.

Estamos, assim, diante de mais uma provocação advinda das lições do agora Foucault professor: que significado pode ter, hoje em dia, uma compreensão da pedagogia como transformação de si mesmo, quando os poderes instituídos apregoam que vivemos no melhor dos mundos e somos livres para fazer o que bem queremos de nossas vidas, bastando para isso apenas adquirir conhecimentos e competências?

Uma resposta consequente parece caminhar para a retomada do que Agamben (2008, p. 117) qualificou como uma dimensão esotérica do cuidado de si, entendida como uma espécie de herança oculta presente no pensamento tardio de Michel Foucault capaz de esclarecer, com outras cifras, o debate pós-metafísico sobre a subjetividade que tanto tem assombrado os pensadores do campo pedagógico. Tudo indica que a recepção atualmente em curso do pensamento foucaultiano, a partir da retomada do cuidado de si, apenas começou a abrir um conjunto renovado de questões e problemas articulados com a preocupação com a formação ética dos sujeitos. Nessa via, temáticas como a espiritualidade, a parresía e a psicagogia, dentre outras, parecem indicar formas de análise que contribuem para desestabilizar os modos pelos quais ainda pensamos os sujeitos e os seus processos de formação, articulando reflexões ontológicas consideradas por muito tempo sem cabimento pelo campo educacional e pedagógico.

Trata-se, ainda, de um reposicionamento radical da reflexão sobre o ser humano, tal como tematizada pelas ciências naturais, biológicas e humanas, redimensionando categorias-chave da gramática pedagógica tais como as noções de pessoa, alma e liberdade, ao mesmo tempo em que põe em movimento nossa compreensão de natureza humana. Consideramos, nesse aspecto, que o aprofundamento dos debates em torno da analítica desenvolvida por Foucault a respeito do cuidado de si é algo crucial, sobretudo, face ao avanço notório das disposições político-epistêmicas 
acionadas pelo atual dispositivo antropológico derivado das chamadas neurociências e sua deriva mais recente, a neurociência da educação. Nesse momento, em que Foucault parece figurar de direito e de fato como um inaugurador de discursos, é fundamental que as leituras que se fazem ao redor de seu pensamento, como sinalizam Puchet e Genis (2010), adquiram o vigor necessário, inclusive, para pensar contra Foucault, o que não deve ser entendido como um mero pensar em oposição, mas como um pensar problematizador que desloque suas ferramentas conceituais para impedir que a própria ética do cuidado de si seja recentrada no âmbito de filosofias educacionais egocentradas tão ao gosto das pedagogias pastorais imbuídas de agregar tudo que aciona o desejo modelador e os poderes normativos da educação.

\section{REFERÊNCIAS}

Agamben, Giorgio. La potencia del pensamiento. Barcelona: Anagrama, 2008.

Alves, Nyrluce Marilia. Os usos pedagógicos da noção de cuidado de si: um estudo sobre a recepção do pensamento tardio de Michel Foucault no campo educacional brasileiro. 2012. 147f.Dissertação (Mestrado em Educação) - Universidade Federal de Pernambuco, Recife, 2012.

Borges-Duarte, Irene. A Fecundidade Ontológica da Noção de Cuidado. De Heidegger a Maria de Lourdes Pintasilgo. Ex aequo, Vila Franca de Xira: APEM, n. 21, p. 115-131,2010. Disponível em: <http://www.scielo.gpeari.mctes.pt/scielo.php?script=sci_ arttext\&pid=S0874-55602010000100009\&lng=pt\&nrm=iso >. Acesso em: 8 jan. 2012.

Carvalho, Alexandre Filordi de. Foucault e a função-educador. Sujeição e experiências de subjetividades ativas na formação do educador. Ijuí: Editora Unijuí, 2010.

Castrillón, Humberto. Foucault, Pedagogo? Revista Educación y Pedagogía, Medellín: Universidad de Antioquia; Facultad de Educación, v.XV, n. 37, p. 201-216, sept./dic. 2003.

Dalbosco, Cláudio. Pragmatismo, teoria crítica e educação: ação pedagógica como mediação de significados. Campinas: Autores Associados, 2010.

Fimiani, Mariapaola. O verdadeiro amor e o cuidado comum com o mundo. In: Gros, F. (Org.). Foucault: a coragem da verdade. São Paulo: Parábola Editorial, 2004. p. 89-128. Foucault, Michel. A hermenêutica do sujeito. 2. ed. São Paulo: Martins Fontes, 2004. O governo de si e dos outros. São Paulo: Martins Fontes, 2011.

GADElHA, Sylvio. Biopolítica, governamentalidade e educação. Introdução e conexões a partir de Michel Foucault. Belo Horizonte: Autêntica, 2009.

Gallo, Silvio. Foucault: (re)pensar a educação.In: Rago, Margareth; VeIgA-Neto, Alfredo (Orgs.). Figuras de Foucault. 2. ed. Belo Horizonte: Autêntica, 2008. p. 253-260.

Gros, Frederick. Situação do curso. In: Foucault, Michel. A hermenêutica do sujeito. 2. ed. São Paulo: Martins Fontes, 2004. p. 613-661.

Herman, Nadja. Formação e experiência.In:Trevisan, Amarildo Luiz; Tomazetti, Elisete; Rossato, Noeli (Orgs). Diferença, cultura e educação. Porto Alegre: Sulina, 2010. p. 80-91.

Kohan, Walter. Sócrates E̊ a educação. O enigma da filosofia. Belo Horizonte: Autêntica, 2011. Muchail, Salma. Foucault. Mestre do cuidado. Textos sobre $A$ hermenêutica do sujeito. São Paulo: Loyola, 2011. 
Nehamas, Alexander. El arte de vivir. Reflexiones socráticas de Platón a Foucault. Valencia: Pre-Textos, 2005.

Noguera-Ramírez, Carlos Ernesto. Foucault professor. In: Reunião Anual da ANPEd, 31., 2008, Caxambu. Anais... Caxambu: ANPEd,2008. Disponível em: <http://www.anped. org.br/reunioes/31ra/1trabalho/GT17-4152--Int.pdf>. Acesso em: mar. 2011.

. Pedagogia e governamentalidade ou da modernidade como uma sociedade educativa. Belo Horizonte: Autêntica, 2011.

Nussbaum, Martha. Love's knowledge. Essays on philosophy and literature. New York: Oxford University Press, 1992.

Ortega, Francisco. Amizade e estética da existência em Foucault. Rio de Janeiro: Graal,1999. PAGNI, Pedro Angelo. Um ensaio sobre a experiência, a infância do pensamento e a ética do cuidado: pensar a diferença e a alteridade na práxis educativa. In: KoHAN, Walter; GondRA, José (Orgs.). Devir-criança da filosofia: infância da educação. Belo Horizonte: Autêntica, 2010. p. 63-79.

. O cuidado de si em Foucault e as suas possibilidades na educação: algumas considerações. In: Souza, Luís Antônio Francisco de; Magalhães, Bóris Ribeiro de; Sabatine, Thiago Teixeira (Orgs.). Michel Foucault: sexualidade, corpo e direito. São Paulo: Cultura Acadêmica, 2011.p. 19-46.

PeÑa, Antonio. Foucault o de la revaloración del maestro como condición de la relación pedagógica y como modelo de formación. Una mirada pedagógica a la Hermenéutica del sujeto. Revista Educación y Pedagogía, Medellín: Universidad de Antioquia; Facultad de Educación, v.XV, n. 37, p. 219-232, sept./dic. 2003.

Pinheiro, Victor. Introdução. In: Platão. O banquete. 3. ed. Belém: Ed. UFPA, 2011.

Portocarrero, Vera. As ciências da vida: de Canguilhem a Foucault. Rio de Janeiro: Editora Fiocruz, 2010.

Puchet, Enrique; Genis, Andrea Díaz (Orgs.). Inquietud de sí y educación. Hacia um replanteo de la filosofía de la educación. Uruguay: Editorial Grupo Magro, 2010.

RAGo, Margareth. Dizer sim à existência. In: .; Veiga-Neto, Alfredo (Orgs.).

Foucault. para uma vida não fascista. Belo Horizonte: Autêntica, 2009. p. 253-268.

Ternes, José. Foucault: Uma história espacial.In: Pommer, Arnildo; Fraga, Paulo Denisar; SchneIder, Paulo Rudi (Orgs.). Filosofia e crítica. Ijuí: Unijuí, 2007. p. 299-312.

Veiga-Neto, Alfredo. Editorial. Revista Educação \& Realidade, Porto Alegre: UFRGS, v. 34, n. 2, p. 5-9, maio/ago. 2009.

\section{SOBRE O AUTOR}

Alexandre Simão de Freitas é doutor em sociologia pela Universidade Federal de Pernambuco (UFPE). Professor adjunto da mesma instituição. E-mail: alexshiva@uol.com.br 


\section{ALEXANDRE SIMÃO DE FREITAS}

\section{A parresía pedagógica de Foucault e o êthos da educação como psicagogia}

O texto aborda a cartografia atual da presença de Foucault, junto aos educadores, em meio aos problemas de recepção e crítica. Parte-se do pressuposto de que, ao abordar o tema do cuidado de si, Foucault produziu insights inovadores que guardam estreitas relações com questões éticas e políticas vitais no âmbito da tradição da Bildung, afetando, por consequência, a representação que temos da pedagogia e das suas categorias, através da diferenciação entre pedagogia e psicagogia. $\mathrm{O}$ fio argumentativo do artigo articula dois movimentos analíticos. Inicialmente, apresentamos uma breve reconstrução da recepção do pensamento de Foucault no campo educacional brasileiro. Em seguida, interpretamos sua análise da psicagogia como um gesto pedagógico a partir do qual emergem novas cifras para a problematização da educação.

Palavras-chave: cuidado de si; Michel Foucault; psicagogia.

The pedagogical parrhesia of Foucault and the educational ethos as psicagogia

This paper addresses the current mapping of the presence of Foucault among educators, amid the problems of reception and criticism. This is on the assumption that, to address the issue of care of the self, Foucault produced innovative insights that have close relations with ethical and political issues which are vital within the tradition of Bildung, affecting therefore the 
representation we have of pedagogy and of its categories, by differentiating between pedagogy and psicagogia. The argumentative thread of the article articulates two analytical movements. Initially, we present a brief reconstruction of the reception of Foucault's thought in the brazilian educational field. Then, we interpret his/its analysis of psicagogia as a pedagogical gesture from which new figures emerge for the problematization of education.

Keywords: care of the self; Michel Foucault; psicagogia.

\section{La parresía de Foucault y el espíritu educativo de la educación como psicagogia}

En este trabajo se aborda el mapeo actual de la presencia de Foucault, junto a los educadores, en medio de los problemas de la recepción e de la crítica. Se parte del supuesto de que, para abordar el tema del autocuidado, Foucault produce ideas innovadoras que mantienen una estrecha relación con aspectos éticos y politicos fundamentales dentro de la tradición de la Bildung, afectando por lo tanto la representación que tenemos de la pedagogía y sus categorías, diferenciando entre la pedagogía y psicagogia. El texto articula dos movimientos analíticos. En primer lugar se presenta una breve reconstrucción de la recepción del pensamiento de Foucault en el campo educativo brasileño. Luego interpretamos su análisis de psicagogia como un gesto pedagógico del que emergen nuevas cifras para la problematización de la educación.

Palabras clave: cuidado de si mismo; Michel Foucault; psicagogia. 